\title{
Top-down or bottom-up: the real choice for public services?
}

\author{
Abstract \\ This article considers two contrasting approaches to reforming public services in order \\ to meet the needs of people living in poverty. The first approach is top-down, involves \\ categorizing individuals (as 'hard to help', 'at risk', etc.) and invokes scientific backing \\ for justification. The second approach is bottom-up, emancipatory, relates to people as \\ individuals and treats people who have experience of poverty and social exclusion as \\ experts. The article examines each approach through providing brief examples in the \\ fields of unemployment and parenting policy - two fields which have been central to \\ theories of 'cycles of deprivation'. It is suggested here that the two approaches differ in \\ terms of their scale, type of user involvement, and the type of evidence that is used for \\ their legitimation. While the paper suggests that direct comparison between the two \\ approaches is difficult, it highlights the prevalence of top-down approaches towards \\ services for people living in poverty, despite increasing support for bottom-up \\ approaches in other policy areas.
}

\section{Introduction}

This article describes two different approaches to reforming public services in order to meet the needs of the most disadvantaged. The first has been influential in the development of welfare policies in the UK in recent years. It is top-down, involves categorizing individuals as 'hard to help' or 'at risk', and invokes the justification of scientific backing and statistics. The second, less frequently-used, approach is bottomup, emancipatory, relates to people as individuals rather than as members of a certain 
category, and treats people who have experience of poverty and social exclusion as experts.

Karelis (2007) has suggested that anti-poverty policies reflect the 'economics of the well-off', and for that reason fail to offer what people living on inadequate incomes need. In particular, he advocates that policy-makers should attempt to place themselves in the position of poor people and consider their needs from this perspective, rather than assuming that policies favouring middle- and upper-class interests (such as those promoting long-term saving) will be appropriate. This approach leads Karelis to suggest that the relief of short-term problems (rather than a focus on longer-term issues) should be promoted for those living precariously on low-incomes in often very difficult circumstances. While his argument is based on economic theory rather than practical examples, one way of testing his argument is to consider these two approaches to public services reform, as the 'bottom-up' approach to public service reform explicitly rejects the 'economics of the well-off', whereas the 'top-down' approach conforms to it.

\section{Reforming public services}

In many areas of public services reform, the Labour government has emphasized the importance of 'choice' and of the need for greater involvement by individuals and communities in determining policies (Le Grande, 2007; Greener, 2003). As this paper will suggest, the 'top-down' approach to reforming welfare services fails to prominently feature 'choice' or participation, except in relation to specific groups such as disabled people and their ability to control services available to them (see, for example, Her Majesty's Government, 2009). In many ways, a more emancipatory bottom-up approach to the reform of welfare services might seem more in keeping with reforms such as 
those designed to promote community empowerment and user involvement in public services.

Two areas of public policy where reform of welfare services is a high priority (and which have been much in the news recently) are increasing employment and removing the barriers that prevent people from working, and supporting vulnerable parents, particularly those receiving social services. These two areas have been chosen as they have been consistently invoked by those advocating the so-called 'cycle of deprivation' approach, which stresses behavioural rather than structural influences on poverty. As Welshman details, this approach has been a strong element of policies towards those living in poverty since the mid-1970s, and continues to be influential within New Labour's policies, alongside a recognition of structural factors (see Welshman, 2007).

This article will briefly consider an example of both top-down and bottom-up approaches in both unemployment and parenting policy. For increasing employment opportunities, the article will consider David Freud's 2007 report 'Reducing Dependency Increasing Opportunity: Options for the future of welfare to work' as an example of the top-down approach, and the work of the Gellideg Foundation in South Wales as an example of the bottom-up approach. For parenting, the Family-Nurse Partnership is taken as an example of the top-down approach, and ATD Fourth World's 'Getting the Right Trainers' project is an example of the bottom-up approach. These four examples differ in their role within policy, with the Freud Report offering a prognosis for reform, the FNP operating as a pilot initiative supplementing existing services, the Gellideg Foundation operating as a third-sector project, and ATD Fourth World involving 
improving training for public servants. As such the examples cover a broad sweep of policy-making activity, but they are similar to the degree that they offer relatively strong exemplifications of the different approaches (in practice, policies are likely to involve a combination of the two approaches).

The aim in describing these examples is not to conduct a comparative evaluation, but to examine the process by which they were developed and agreed, and how this might influence the sustainability and success of each approach. Apart from anything else, the difference in scope and resources means that comparison in terms of outputs would be impossible. The examples are thus used in an illustrative manner, rather than as a basis for producing generalisable conclusions. This article does, however, contrast the four examples by considering three elements which differentiate them: scale, user involvement, and the type of evidence used for legitimation of the top-down and bottom-up approaches.

\section{Different approaches to reforming services for those out of work}

\section{The Freud Report}

David Freud was commissioned by the Department for Work and Pensions to "undertake a wide-ranging review" of the government's welfare strategy in October 2006. His review set out to cover three areas: the design of welfare to work policy; the devolution of welfare to open up new opportunities for delivering employment services to some of the most disadvantaged communities; and how to build a more effective market in the provision of employment services. This was seen as leading to a more 
customer-focused welfare delivery system that would better reflect the Government's wider public service ambitions of greater choice and empowerment.

Freud, an investment banker by profession who stated that he "didn't know anything about welfare at all when [he] started", allegedly took three weeks to research and write a first draft of his report which was eventually published in March 2007 (Telegraph, 2008). Many of the Freud Report's recommendations were incorporated into the government's Welfare Reform Bill in December 2008.

During the preparation of the report, Freud met with a wide range of contractors who delivered welfare services. Significantly, he did not appear to solicit the views of those out of work or of those organizations such as unemployed workers' centres, which represented them. Despite being commissioned to 'reflect the Government's wider public service ambitions of greater choice and empowerment' in his report, Freud's approach appeared to prioritise learning from providers of welfare services, rather than their users.

Freud recommended that greater use be made of the private and voluntary sectors, with public money being given to one leader provider for each region to deliver welfare services, a set up which guaranteed that the lead contractor for each region would be a private contractor with voluntary sector groups sub-contracting. The sustainability of an approach which will involve private sector contractors setting up services in areas where they have no previous experience of working is yet to be determined. Some have promoted caution in the use of these contractors, drawing on comparative data (Finn, 2009, CPAG, 2008), but the authors have been unable to find significant UK-based research on this topic. 
Freud's other key recommendation was an increase in the use of conditionality, with greater obligations on claimants to seek work. It could be surmised that some of those bodies that were involved in the drafting of the report may, in the future, be able to participate in bidding for the delivery of new services. In contrast, those that were not involved (i.e., in large measure, recipients of the benefits concerned) will receive greater sanctions and conditions on the money that they receive from the state.

Freud's discussion of the recipients of welfare is innovative in its categorization of them as not merely 'hard to reach', but also 'hard to help' (see for example Freud, 2007, p.5, 6). He also refers to the 'perception' that moving into work does not pay (ibid. p.9), when for many people this is not merely a perception but reality, particularly in the face of low-paid and insecure jobs (for a review of some recent research covering this issue, see Goulden, 2010). Although the Government's consultation on the Welfare Reform Bill did appear to involve some unemployed people, comparative data has not been provided on exactly who was consulted, their socio-economic status, etc. Furthermore, those comments reported in the text (Appendix A to the Bill) overwhelmingly appear to reinforce the Freud report's emphasis on private-sector contracting and conditionality, and the vast majority appear drawn from organisations and individuals which do not represent service users (Department of Work and Pensions, 2008).

\section{Gellideg}

Freud's top-down approach to reforming services for those out of work contrasts strongly with more bottom-up approaches which have stressed the involvement of service users and which have been developed over a far longer time-period. 
One example of the latter is that put forward by the Gellideg Centre, based in the Gellideg Estate, a traditionally high-unemployment, high-crime area of Merthyr Tydfil in South Wales. It was founded in 1998 by a group of local residents with the backing of Rhondda Cynon Taff, Groundwork Merthyr, and Oxfam. The resulting Gellideg Foundation Group successfully bid for European Regional Development funding to carry out environmental improvements and other activities on the estate, following extensive consultation with local residents. These consultations were undertaken using 'participatory appraisal', which enabled a detailed assessment of the barriers faced by local residents when trying to make a living.

Although it is difficult to assess impact from such relatively small-scale initiatives, the creation of the Gellideg Centre has coincided with, and possibly helped to produce, a significant change in the Estate. According to the New Economics Foundation, South Wales Police have maintained that the local crime rate has slumped by $34 \%$ (albeit over an unspecified period), and the number of void properties on the Estate fell well below the national average (New Economics Foundation, 2000: 6). Following on from this work, the Gellideg Foundation concentrated on tackling unemployment on the Estate. Since 2002, it has developed a multi-faceted programme to "make opportunities available and accessible to men and women who have previously found the transition from welfare dependency to paid work insurmountable." This approach has explicitly involved service users (i.e. the unemployed) as experts on the barriers which they face and the means by which they might be overcome (Buhaenko et al. 2003: 19).

Crucially, the Gellideg approach acknowledges and challenges deep-rooted power imbalances within the Estate - in particular, the prevalence of gender stereotyping of 
women and the impact this has on their job prospects (ibid.). A willingness to engage with such wider issues has been evident in a number of other relatively successful community-based projects, such as the Clydebank Independent Resource Centre (Collins, 2008). As Bennett and Roberts note, the recognition of deep-rooted power relationships may pose problems for policy makers" because they then have to think about how to change power relations at the community, household or intra-household level" (2000: 10). Nonetheless, engagement with such issues, often keenly felt by local residents, may produce more sustainable approaches to the reduction of poverty.

\section{Different approaches to reforming services to aid parenting}

\section{The Family Nurse Partnership}

The Family Nurse Partnership (FNP) provides individual family nurses to low-income, first-time young mothers (particularly teenage parents), who are classified as 'at-risk' in some way, over a two to three year period. The FNP initially operated as a pilot under the aegis of the Department for Children, Schools and Families, and has now been extended to fifty pilot sites, with others to be set up from July and September of this year. Nurses carry out a programme of structured visits to the mother in pregnancy and after the child is born. The FNP is focused on the mother's behaviour, with the nurse being required to coach her in parenting and in obtaining training, education and/or employment and to act as an information source for women to access services (Smith, 2006; SEU, 2006: 52).

FNP is modelled on its homologue in the United States (the 'Nurse Family Partnership'), a programme which has been operating for thirty years across a number of states. 
Unlike its US counterpart, one of the main public rationales for the development of the UK FNP programme is the fact that low-income, first-time mothers may feel more comfortable interacting with health professionals rather than social workers or other state employees (Armstrong, 2006).

Proponents of the FNP do however share with the American programme's supporters a focus on the 'scientific evidence' for the effectiveness of the programme, as proved through clinical trials undertaken in a variety of settings (Olds et al., 2002, 2007). Such trials have tested the relationship between participation in the programme and everything from kidney problems to promiscuity (SEU, 2006:52). The founder of the scheme has maintained that the results of these clinical trials distinguish this approach to social policy from more traditional ones such as the provision of benefits through income transfers (e.g. child benefit). Indeed, he has maintained that only those programmes which have been tested through randomized trials are worthy of state support, since only these are "effective and thus moral" (Olds, 1996: 3).

The Family Nurse Programme coheres with a larger social policy agenda which has involved categorizing individuals as 'at risk', that small minority of people who face 'complex and multiple problems' (cf Social Exclusion Task Force, 2007: 4).

\section{ATD Fourth World}

ATD Fourth World is a non-governmental organization with no religious or political affiliation which engages with individuals and institutions to find solutions to eradicate extreme poverty. It is a member of the International Movement ATD Fourth World. Working in partnership with people in poverty, ATD Fourth World's human rights- 
based approach focuses on supporting families and individuals through its grass-roots presence and involvement in disadvantaged communities in both urban and rural areas, creating public awareness of extreme poverty and influencing policies to address it.

In 2005, the Department of Health funded a project to create and implement a trial training programme for social workers, with some people living in poverty acting as trainers and being involved in the design of the training programme. The 'Getting the Right Trainers' project was intended to reflect the significance of poverty within the circumstances surrounding children becoming involved with social care services. The project was also intended to increase awareness of the impact of poverty when making decisions about social work interventions (Gupta and Blewitt, 2005). Family members who had experienced poverty were given training to develop their training skills and build their confidence throughout the two months of the pilot training programme.

The majority reaction of social workers was positive, valuing the knowledge and insight gained and finding the role of service users as experts challenging and stimulating, though a significant minority felt it was 'patronising' or 'basic', in some cases reflecting social workers' approach to social work as concerning 'maintenance' rather than 'emancipation'.

Some of the key findings of this project, confirmed by other participatory projects, is that participation is a process, not just a one off event; that people need the right support to be able to take part; and that tackling poverty is about dignity and self-respect, not just money (ibid.).

\section{Making decisions about policy}


The four examples given above differ radically across three dimensions: scale or scope; user involvement; and the type of evidence used to legitimate them. The difference in scale or scope of the policies is particularly marked. The Freud Report and the FNP constitute nationally-supported programmes (although clearly, Freud's welfare proposals are of a significantly greater magnitude in terms of the number of participants and amount of funds involved than the FNP, which is still at test stage in around fifty pilot areas). In contrast, the Gellideg and ATD Fourth World projects were relatively small in scale. It might be suggested that the participatory methods used in the latter examples cannot be applied to national policy. However, a participatory approach has been promoted by the EU as a crucial element of policy-making in the area of social exclusion. Hence, the Bridging the Policy Gap project explicitly acknowledged the importance of involving those with experience of poverty in developing national as well as local policy. This project used the "European concept" of a "peer review" to investigate participants' experience of how national policies were being implemented, and whether these policies adequately met locally-defined needs (Mackenzie and Kelly, 2008: 37).

The examples also differ in terms of who drove their development, and in the type of evidence and knowledge they drew on during the development stage. Freud's Report, and to a lesser extent the FNP, were developed by Government or Governmentappointed figures during a relatively short time-scale (albeit following a long period of development in the US, in the case of the FNP). Neither involved service-users extensively in their development. In contrast, the Gellideg and ATD Fourth World approaches explicitly included service-users as key decision-makers. 
As noted above, the top-down approach seems to run against the grain of other areas of policy, where the focus is increasingly on involving service-users in consultations and sometimes directly in decision-making (Involve, 2007). It is difficult to compare the extent of participation across Departments and policy areas, as little reliable comparative data is available. One rough measure compares the number of consultation responses received in different policy fields and we would (tentatively) suggest that there appears to be less consultation of service users living in poverty than for many other Government services.

For example, 1,125 responses were received to the GfK NOP consultation on the new Welfare Reform proposals (DWP/GfK NOP, 2008: 4), of which 136 were staff responses and 290 were from the 'Netmums forum' (the number of 'service users' consulted is not clear from the report). Although as previously suggested it is difficult to make direct comparisons, the authors have roughly calculated that around 107,926 individuals were involved in consultations for the Department of Transport in 2007-8 (Hansard, 2008a), and around 26,539 in consultations for the Department for the Environment, Food and Rural Affairs (Hansard, 2008b), the only two Departments for which robust figures could be found ${ }^{1}$. Of course, the two latter Departments arguably serve the entire population, unlike welfare reform which only affects some people; and a number of different policies were being consulted on in each case. Nonetheless, the disparity between the numbers involved in the consultation on welfare reform and in these consultations is suggestive.

\footnotetext{
${ }^{1}$ Calculated from tables A, B and C in Hansard, 2008a and table given in Hansard, 2008b, respectively.
} 
Secondly, both the FNP and, to a lesser extent, the Freud proposals, appeal to numerical, cross-sectional data for legitimation. Hence, the FNP's founder and its UK Government supporters have been keen to report the FNP's performance as evidenced through Randomised Control Trials, whilst the Freud report attempted to develop some parameters for statistical modelling of the impact of labour market interventions, which it appeared to suggest would support its promotion of contracting and conditionality.

These technologies are presented as a 'neutral', scientific means of bolstering the legitimacy of both policies. However, there is a need for extreme caution when interpreting such statistics. As Macdonald and Marsh have argued, there is a danger of interpreting the correlation of factors as leading to irreversible causal processes, when in reality individuals' lives may exhibit large degrees of indeterminancy (2005: 67).

Different 'risk factors' may or may not lead to certain outcomes, depending on how they are interpreted and lived by individuals and the existence and timing of critical junctures.

A lack of awareness of the complexity of individuals' experiences of poverty perhaps underlies the use of potentially unhelpful categories used within both the FNP and Freud report (such as families 'at-risk' and those who are 'hard to help'). These categories not only potentially stigmatize individuals but can also lead to the creation of ineffective or unsustainable policy. Freud's apparent assumption, for example, that individuals who are out of work and claiming benefits are necessarily 'hard to help' leads us away from any analysis of issues related to the availability (or otherwise) and quality of work available. These issues are increasingly salient for workfare approaches as Britain experiences, and begins to climb out of, recession (Goulden, 2010). 
The involvement of those with experience of poverty in establishing, delivering or reviewing policies and services helps guard against this problem. As Bennett and Roberts have suggested, incorporating individuals with experience of poverty enables a detailed knowledge of the causal mechanisms underlying poverty and its persistence (Bennett with Roberts, 2004). Policies and theories concerning poverty, as in most other areas, have typically been developed by those from "the financially comfortable classes" (Karelis, 2007: 105). Perhaps as a result, policy-making has often failed to tackle the underlying mechanisms producing and sustaining poverty. This argument has been accepted in many other fields, where the involvement of existing networks and clients of certain policies is seen as increasing their sustainability (as in the extensive corpus of academic work concerning involvement of regulatees in the drawing-up of regulations; see for example Black, 1997).

\section{Conclusion}

Although this article aims only to describe, rather than to compare these two approaches towards welfare service reform, the examples given do suggest some of the opportunities which a more bottom-up approach to reform would offer. We do not argue, however, that the bottom-up approach is a panacea for public services reform.

Tensions and disagreements between people who deliver services and service users can be difficult to resolve. Particular community-led initiatives can rely heavily on one or two individuals, resulting in 'overload' (Smith, 2008). Such participants can be taken for granted, with the possibility that they start to be treated effectively as "unpaid community professionals” (Anastacio et al. 2000, p.62). Many 'participatory’ initiatives have focussed on relatively minor issues related to service delivery, rather than 
including within their scope more radical and significant change (Turner et al., 2009). Even when local initiatives have been effective, government has traditionally found it difficult to support genuine local solutions while achieving national impact and scale (Bunt and Harris, 2010).

In 1988, the Conservative Secretary of State for Environment Nicholas Ridley recommended a top-down, market-based model of public service reform for all welfare services, where the role of the state was to sign the contracts and let other providers get on with delivering the work (Ridley, 1988). Over the past twenty years, this idea has moved from the fringes of political debate, not taken seriously by most decisionmakers, to an orthodoxy which is now accepted by the leaderships of all the main political parties. It is theoretically possible that the next twenty years will see bottomup, emancipatory service reform develop in a similar way. For this to happen, the drive towards greater participation in universally provided public services, such as health care, local government and community safety (Involve, 2007) also needs to inform policy-making for those services targeted at people living in poverty.

\section{References}

Anastacio, J., Gidley, B., Hart, L., Keith, M., Mayo, M. and Kowarzik, U. (2000) Reflecting realities: participants' perspectives on integrated communities and sustainable development, Bristol: Policy Press.

Armstrong, H. (2006) 'Interview for Epolitix', accessed on $14^{\text {th }}$ January 2007 at www.epolitix.com/EN/Interviews/200609/131229c8-3dae-4e53-9bfbf35795c82787.htm

Bennett, F. with Roberts, M. (2004) From Input to Influence: Participatory Approaches to Research and Inquiry into Poverty, York: Joseph Rowntree Foundation.

Black. J. (1997) Rules and Regulators, Oxford: Oxford University Press. 
Buhaenko, H., Flower. C. and Smith, S. (2003) Fifty Voices are Better than One; Combating Social Exclusion and Gender Stereotyping in Gellideg, in the South Wales Valleys, Oxford: Oxfam and Gellideg Foundation Group.

Bunt, L. and Harris, M. (2010) Mass Localism. London: NESTA.

Child Poverty Action Group (CPAG) (2008) Press release: £75bn private welfare contracts must not take away family security rights, 27th February, London: CPAG

Collins, C. (2008) The Right to Exist: The Story of the Clydebank Independent Resource Centre, Clydebank: Clydebank Independent Resource Centre/Oxfam.

Department for Work and Pensions (2008) Raising expectations and Increasing Support: Reforming Welfare for the Future, Cm 7506, London: HMSO.

Goulden, C. (2010) Cycles of poverty, unemployment and low pay, Joseph Rowntree Foundation Roundup, London: Joseph Rowntree Foundation.

Greener, I. (2003) 'Who Choosing What? The Evolution of the Use of 'Choice' in the NHS, and its Importance for New Labour' in Bochel, C., Ellison, N. and Powell, M. A., eds., Social Policy Review 15: UK and International Perspectives. Bristol: The Policy Press.

Hansard (2008a) Written response from Jim Fitzpatrick M P to Theresa May MP, in Hansard, House of Commons, 10th June, Cols. 158-62.

Hansard (2008b) Written response from Jonathan Shaw MP to Theresa May MP, in Hansard, House of Commons, $1^{\text {st }}$ July, Cols.769W- 772W.

Finn, D. (2009) 'The welfare market and the flexible New Deal: lessons from other countries', Local Economy, vol.24 issue 1: 38-45.

Freud, D. (2007) Reducing Dependency, Increasing Opportunity: Options for the Future of Welfare to Work: An Independent Report to the Department for Work and Pensions, London: HMSO.

Gupta, A. and Blewett, J. (2005) 'Involving services users in social work training on the reality of family poverty: A case study of a collaborative project', Social Work Education, vol.27 issue 5: 459-73.

Her Majesty's Government (2009) Welfare Reform Act 2009, London: HMSO.

Involve (2007) Participation Nation: Reconnecting Citizens to the Public Realm, London: Involve.

Karelis, C. (2007) The Persistence of Poverty: Why the Economics of the Well-Off Can't Help the Poor, New Haven: Yale University Press.

Le Grand, J. (2007) The other invisible hand: delivering public services through choice and competition. Princeton, N.J.: Princeton University Press. 
Macdonald. R. and Marsh, J. (2005) Disconnected Youth?: Growing Up in Poor Britain. Basingstoke: Palgrave Macmillan.

Mckenzie, S. and Kelly, P. (2008) From the Local to the National: Bridging the Policy Gap in Social Inclusion. Glasgow: Poverty Alliance.

New Economics Foundation (2000) Prove it! Measuring the Effect of Neighbourhood Renewal on Local People. London: Groundwork, New Economics Foundation and Barclays Plc.

Olds, D.L., Kitzman, H., Hanks, C., Cole, R., Anson, E., Sidora-Arcoleo, K., Luckey, D.W., Henderson, C.R., Holmberg, J., Tutt, R.A., Stevenson, A.J. and Bondy, J. (2007) 'Effects of nurse home visiting on maternal and child functioning: age-9', Pediatrics, issue 120: 832-845.

Olds, D.L., Robinson, J., O'Brien, R., Luckey, D.W., Pettitt, L.M., Henderson, C.R., Ng, R.K., Sheff, K.L., Korfmacher, J., Hiatt, S. and Talmi, A. (2002) 'Home visiting by paraprofessionals and by nurses: A randomized, controlled trial', Pediatrics, issue 110: 486-496.

Olds, D. (1996) 'Review of 'Starting right: How America neglects its youngest children and what we can do about it", Social Service Review, vol. 70 issue 4.

Ridley, N. (1988) The local right. London: Centre for Policy Studies.

Smith, A. (2008) 'Applying the lessons learnt: Community Involvement in Regeneration', Public Policy and Administration, vol.23 issue 2: 145-2.

Smith, C. (2006) 'Mom school: Fixing children's services is only half the battle', New York Metro, $20^{\text {th }}$ February.

Social Exclusion Task Force (2007) Reaching Out: Think Family, London: Cabinet Office, HMSO.

Social Exclusion Unit (2006) Reaching Out: An Action Plan on Social Exclusion, London: Cabinet Office, HMSO.

Turner, E., Dodds, A. and Paskins, D. (2009) ' Power to the People'? The Limitations of the 'New Localism' as a Means of Community Empowerment', Paper presented to PSA Local Politics Specialist Group, Birmingham University, January 2009.

Telegraph (2008) Interview: David Freud tells Rachel Sylvester and Alice Thomson how the private sector can get Britain back to work. $4^{\text {th }}$ February.

Welshman, J. (2007) From Transmitted Deprivation to Social Exclusion: Policy, Poverty and Parenting, Bristol: Policy Press. 